\section{La Revista Proposiciones: Espacio de sociabilidad intelectual y producción de saberes en el campo intelectual de la izquierda chilena durante los $80^{*}$}

The Journal Proposiciones: space of sociability and production of social knowledge in the intelectual field of the chilean left during 1980s.

\section{Cristina Moyano-Barahona \\ Marcelo Mella-Polanco**}

\section{Resumen}

En este artículo se explora la relación entre los procesos de producción de conocimiento para la acción en el campo de la oposición al Régimen de Pinochet y el contexto político enunciativo marcado por la necesidad de

Resultados investigación Proyecto Fondecyt 1150049.

** Departamento de Historia- Universidad de Santiago de Chile, Av. Libertador Bernardo Ohiggins 3363, Estación Central. Correo electrónico: cristina.moyano@usach.cl marcelo mella@usach.cl. superar la Dictadura. Particularmente, nos concentraremos en estudiar la Revista Proposiciones, como parte de uno de los espacios de sociabilidad político intelectual surgido en los años 80 , que concentró a un amplio espectro de la izquierda renovada, para explorar las características del campo intelectual de oposición, los debates surgidos dentro de la izquierda que experimenta procesos de renovación y la revista como factor político en la construcción de tipos de saberes y sentidos comunes que formaron parte de la transición a la democracia. Metodológicamente, la revista fue analizada como texto, como soporte y como red, complementando los resultados con entrevistas en profundidad.

Palabras clave: campo intelectual, ONG, revistas políticas, izquierda.

\begin{abstract}
This article discusses the relationship between knowledge production processes for action in the field of opposition to the Pinochet regime and the political enunciative context marked by the need to overcome Dictatorship. The analysis will focus particularly on the study of the Proposiciones journal, one of the places of intellectual-political sociability, which emerged in the 1980s and that attracted a broad spectrum of the renewed left. Its aim is to explore the characteristics of the opposition's intellectual field, the debates within that space as a political element in the construction of knowledge and meanings that later on became part of the process of transition to democracy. From a methodological point of view the journal is first analyzed as a text, as a support and
\end{abstract}


afterwards as a network and the results were complemented with in depth interviews.

Key words: intelectual field, NGO, political journals, the left.

\section{Introducción}

"Compañero, las hipótesis son para el que las trabaja" (Vicente Espinoza, Entrevista 2015)

El campo intelectual del Chile de los largos años 60 fue duramente golpeado por la irrupción de los militares en 1973. Los espacios de creación de conocimiento, alojados mayoritariamente en universidades que estaban viviendo importantes procesos de modernización y democratización, se habían convertido en instituciones que con relativa autonomía- aportaban al debate político y social de la época (Garretón 2014). La búsqueda de las razones del subdesarrollo económico y social de la nación, las interrogantes por los límites de un modelo de crecimiento que mostraba con fuerza su agotamiento, así como las preguntas sobre las transformaciones en la estructura social, eran, por cierto, las principales preocupaciones que compartían aquellos intelectuales que poblaban estos centros académicos (Beigel 2013:113). Sociólogos, economistas, historiadores, filóso-fos, politólogos -chilenos y extranjeros- dialogaban, debatían, organizaban coloquios, talleres y publicaban sobre las problemáticas de un Chile que aparentemente se encon-traba en la encrucijada de sus propios límites (Brunner 1985). Tanto la propuesta de "la revolución en libertad", encarnada por el demócrata cristiano Eduardo Frei Montalva (1964-1970), como la "vía chilena al socia-lismo" de Salvador Allende (1970-1973), fue-ron expresión de la intrincada relación entre política y conocimiento social. Centros como la CEPAL proveyeron de los principales elementos para el programa económico reformista de Frei, demostrando el fértil diálogo entre cientistas sociales y políticos que caracterizó la larga década. DESAL, por su parte, a través de la "teoría de la marginalidad", habría permitido pensar las formas de incorporación de los sectores po-pulares a los procesos de modernización social en ese mismo gobierno. Más tarde, centros como el CEREN (Rivera 2015) -alojado en la Universidad Católica- o el CESO - parte de la Universidad de Chile (Lozoya 2015), entregaban valiosos elemen-tos para la "vía chilena al socialismo", tanto en la dimensión de la transformación cultural, requerida para una revolución en democracia, como aspectos para una nueva economía definida como no capitalista (Devés 2003).

Paraalgunosanalistas-actores del proceso-esta imbricada relación tuvo un componentenegativo, ya que los centros habrían actuado más como "faros ideológicos" que como pro-ductores de conocimiento social y, teñidos con altas cuotas de dogmatismo, habrían impedido anticipar la reacción conservadora que culminó con el Golpe de Estado (Garretón 2014). Sin embargo, más allá de esta crítica -atendible, por ciertonos interesa destacar la existencia de un campo intelectual en ebullición, con actores nacionales e internacionales en permanente circulación, con espacios constituidos para la generación de saberes, donde la interdisciplinariedad confluía en talleres, publicaciones y congresos y en el que alumnos en formación, compartían espacios con intelectuales de la talla de Aníbal Pinto, Fernando Cardoso, Armand Mattelart, André Gunder Frank, Franz Hinkelammert, Enzo 
Faletto, Ruy Mauro Marini, entre otros, sobre el Chile presente y el por venir (Devés 2003), y que fue abruptamente terminado con la asonada del 11 de septiembre de 1973.

Con la llegada de los militares, se transformaron profundamente las formas de generación de conocimiento, el rol del intelectual y las estrategias de difusión y de configuración de los debates. Observados de cerca por los aparatos represivos, los intelectuales tuvieron que abandonar su función pública. Con la prohibición de publicar, orquestada desde la División Nacional de Comunicación Social (DINACOS) (Eloy 2014), un manto oscuro tiñó la creación y circulación de conocimiento desplazándola a la marginalidad más absoluta. La represión y las violaciones masivas a los derechos humanos reorientaron las preocupaciones más urgentes hacia el campo de la denuncia y la sobrevivencia, y no será sino hacia fines de esa década cuando un nuevo campo político intelectual comience a mostrar su primera fisonomía (Subercaseaux 2000).

Este nuevo campo estuvo constituido por intelectuales formados en el período previo al Golpe o que culminaron sus estudios durante los primeros años de la Dictadura militar. Principalmente sociólogos, filósofos, economistas, trabajadoras sociales, y cientistas políticos, se dieron a la labor de restituir el acto público de crear conocimiento para revincularlo con la actividad política (Iglesias 2015: 228). Con variadas dificultades, encuentros y desencuentros, este campo participó de varias premisas comunes sobre la forma de producir conocimiento y la vinculación de la ciencia con el mundo social. En ese sentido, explorar estos aspectos nos parece sustancial para comprender también los dilemas epistemológicos entre ciencia, verdad y política.
En este artículo nos concentraremos en estudiar la Revista Proposiciones, uno de los espacios de sociabilidad político intelectual surgido en los años $80^{1}$ y que concentró al gran universo de la izquierda renovada, para responder tres preguntas claves: ¿Qué características tuvo este campo intelectual de oposición a la dictadura? ¿Qué cambios experimentó durante los años 80 ? y ¿cómo se representaron éstos en la revista Proposiciones?

En términos metodológicos se revisaron los números editados entre 1980 y 1990, en tres dimensiones: autores, debates y características del soporte comunicacional. En conjunto con ello se realizaron 4 entrevistas a intelectuales del mundo de las ONG, dos directamente vinculados con Sur: Paulina Saball y Vicente Espinoza, y otras dos a intelectuales de ECO (Educación y Comunicaciones) que fueron parte de la red con la que se vinculó Sur: Mario Garcés y Fernando Ossandón. Estas entrevistas se usaron para complementar aspectos subjetivos de las dinámicas de asociatividad que tuvo el campo intelectual de oposición en los años estudiados y relevar la importancia que tuvo la revista Proposiciones en la memoria de los intelectuales.

\section{El nuevo campo intelectual en sus inicios.}

Al alero de la Iglesia Católica y en particular, de la Vicaría de la Solidaridad, varios cientistas sociales encontraron un espacio para intervenir y reflexionar sobre los profundos cambios que experimentaba Chile (Garcés 2010). Hacía fines

A partir de marzo de 1981, se inicia una segunda etapa en el área de las publicaciones. En el artículo 24 de la nueva Constitución de 1980 , se indicada que era rol del Ministerio del Interior regular la fundación, edición y circulación de nuevas publicaciones. 
de la década de 1970, había surgido un nuevo tipo de espacio desde el cual se podía ayudar a los más golpeados por la Dictadura, pero también reflexionar sobre las transformaciones sociales, la asociatividad popular, el modelo económico y los cambios en la cultura política nacional. Así numerosas Organizaciones No Gubernamentales (ONG) y Centros Académicos Independientes se dieron a la inmensa tarea de desentrañar los cambios estructurales y comprender la nueva sociedad emergida de la combinación entre represión político social y nuevo modelo económico neoliberal (Bastías 2013:116).

Financiadas mayoritariamente desde el exterior (Bastías 2013), estos organismos configuraron un interesante espacio político académico (Jocelyn Holt 2000), en el que combinaron la acción de intervenir sobre el espacio sociopopular (Agurto 1988) y la reflexividad de la propia práctica de intervención. Sin publicaciones tradicionales, pero activando redes sociales, el mundo de las ONG y los Centros Académicos Independientes, volvieron a generar un campo intelectual, distante del conocido en la larga década de los 60, pero con algunas continuidades importantes. Por ejemplo, promovieron un conocimiento generado a partir del contacto directo con la realidad; articularon prácticas de generación de conocimiento donde los talleres ocuparon un lugar central; desarrollaron la interdisciplinariedad en la generación de saberes y participaron de la idea de que el conocimiento debía ser útil para el mejoramiento de las condiciones de vida de los sectores populares. Sin embargo, pese a esas conexiones con el pasado, las diferencias fueron significativas, ya que el conocimiento se generó mayoritariamente fuera de las universidades; circuló en espacios reducidos y por medio de publicaciones con carácter "restringido" o como boletines internos, sin tener resonancia en los escasos medios de comunicación de masas oficiales y, por último, no tuvo como principal objeto de referencia al Estado. Es decir, no fue un conocimiento que aspirara a incidir en las políticas públicas, sino que por sobre todo, buscaba nutrir los nuevos repertorios de sociabilidad popular, de espaldas a las instituciones gubernamentales (Garcés 2015), donde articular el eje "entre realidad y proyecto de transformación no es otro que la constitución del pueblo como sujeto histórico" (Ossandon 1983:17)

Sin embargo, pese a las numerosas restricciones y peligros que conllevaba la generación de conocimiento sobre lo social (Eloy 2014), muchos cientistas sociales opositores a la Dictadura Militar, organizaron sus vidas para dar sentido a una nueva forma de vincular el saber con las transformaciones que experimentaban los actores sociales (Garcés 2010). Con partidos en clandestinidad o funcionando desde el exilio, muchos de estos cientistas sociales se dieron a la labor de articular un espacio de reflexión en el Chile de los 80, que permitiera dotar de nuevos significados a la izquierda y a la oposición en su conjunto, constituyendo un interesante campo intelectual, que no ha sido lo suficientemente abordado por la historiografía nacional (Puryear 1994) $)^{2}$. Varios de estos intelectuales estaban viviendo procesos de ruptura o de renovación de sus antiguas militancias- particularmente con aquellos partidos generacionales surgidos a fines de los años 60- y resignificaron esta práctica de creación de conocimiento e intervención social como un tipo particular

Diferenciamos aquí la creación de boletines o revistas creadas por los partidos para sus militantes o simpatizantes y que circularon en Chile o en el exterior con objetivos informativos o de propaganda y que forman parte de otro componente del campo político. 
de militancia. Según Bastías, "muchos profesionales de las instituciones de apoyo actuaron autoconscientemente como una intelectualidad de vanguardia, siguiendo más o menos explícitamente la teoría gramsciana al autoidentificarse como promotores de una nueva hegemonía popular" (2013: 134)

Lejos de ser un campo político intelectual disociado de los debates que circulaban en el Cono Sur - varios de cuyos países estaban viviendo los inicios de sus procesos de recuperación democrática - los intelectuales de izquierda que permanecieron en Chile, organizaron esfuerzos y articularon densas redes, sobre las cuales circularon debates, reflexiones y propuestas para repensar la sociedad chilena y el rol que le competía a la izquierda en este nuevo contexto (Moyano 2011). Así también se dieron a la tarea de pensar un Chile en democracia y los caminos posibles de una futura transición. A partir de ese inmenso desafío y muchas precauciones, rearticularon el campo intelectual de oposición y repusieron lo político en el debate público (Moyano 2016).

Sin entrar en la importancia que tuvieron en este proceso las revistas políticas disidentes, de circulación nacional, como lo fueron APSI, Análisis, Hoy o Cauce (Moyano 2009), nos centraremos en una revista de carácter académico, a través de cuyas huellas delinearemos las redes, los debates, las prácticas de sociabilidad y de lectura, que un sector de la izquierda nacional supuso como clave para renovar la política. Nos referimos a la revista Proposiciones, editada por Sur profesionales, ONG de gran importancia, tanto por los intelectuales y políticos que transitaron por dicho espacio, como por los debates que en ella se registraron y que cruzaron las fronteras nacionales, conectando el saber de una izquierda en renovación, con las nuevas categorías y problemáticas de la izquierda no comunista occidental y los debates que desde el exilio, otros intelectuales buscaban hacer llegar a Chile. Para nosotros, la Revista Proposiciones es clave para interpretar los contenidos de este campo intelectual, ya que actuó: i)como espacio de institución de debates y repertorios; ii) incluyendo y excluyendo actores y iii) como factor de transformación del mismo campo de oposición.

Con ello, queremos demostrar que el debate político intelectual de oposición al interior de Chile estuvo lejos de ser un campo marginal, reducido y condenado a una oscuridad ideológica, sino que muy por el contrario, fue un espacio de intensos debates, de extensas redes y de circulación de nuevas ideas y lecturas diversas, que permiten dibujar una nueva imagen del Chile dictatorial. En dicho campo, un nuevo tipo de intelectual estaba en constitución: aquel que marcado por las restricciones dictatoriales hizo de la reflexión un acto de oposición y de la práctica de intervención social un hecho político. Mismo actor, que hacia la postrimería de la década mutaría en el experto alejado del intelectual comprometido.

\subsection{La ONG Sur. Algunas referencias contextuales.}

Sur, Centro de Estudios Sociales y Educación, nació en 1978 como un proyecto político académico en el que un conjunto de profesionales e intelectuales se dieron a la tarea de investigar y estudiar la realidad nacional y latinoamericana. Alfredo Rodríguez ${ }^{3}$, José Bengoa ${ }^{4}$, Eugenio

Arquitecto, experto en temas de urbanismo y ciudad, fue también militante del MAPU y uno de los fundadores de SUR.

4 Antropólogo, experto en temas de cultura mapuche y movimientos sociales, fue militante del MAPU y uno de los fundadores de SUR. 
Tironi $^{5}$ y Javier Martínez ${ }^{6}$, fueron sus socios fundadores, todos con vinculaciones, presentes o pasadas, al Movimiento de Acción Popular Unitaria (MAPU).

Desde la naciente institución, estos intelectuales convocaron a nuevos actores para participar del desarrollo del Centro de Documentación sobre la realidad nacional y de un Taller de Coyuntura, que procesaba la información acopiada y de la cual nacieron dos boletines: el Correo del Sur y Hechos Urbanos, además de la Revista Proposiciones (http://www.sitiosur.cl/ publicacioneshistoriaproposiciones.php). Las primeras reuniones realizadas en Sur estuvieron fundamentadas en lazos de conocimiento previo y algunas premisas políticas compartidas, cercanas a lo que más tarde condensó como Renovación Socialista. De allí, que las dinámicas iniciales de generación de conocimiento, así como los debates político- teóricos, estuvieran marcadas por ese sino crítico de la actuación de la izquierda durante la Unidad Popular, el fuerte distanciamiento al dogmatismo marxista - que habrían abrazado algunos intelectuales en los años 60 y 70- y la dura crítica a la instrumentalización que hicieron los partidos políticos de los movimientos sociales populares.

La participación de intelectuales fue en aumento a lo largo de los años 80, cuando Sur había alcanzado cierto reconocimiento como centro productor de saberes. La adscripción y participación de profesionales y expertos tenía cierta flexibilidad. Algunos de ellos fueron

Sociólogo, experto en teoría política, militante del MAPU y posterior experto en comunicaciones estratégicas. También fue uno de los fundadores de Sur. de SUR y dedicado a temas de transformaciones estructurales de la sociedad chilena.

invitados a colaborar con la institución y luego fueron contratados como profesionales de la misma. Tal es el caso de Vicente Espinoza, sociólogo, que tenía a su cargo un taller con pobladores asociado a la Vicaría de la Solidaridad y quien, después de un conflicto con el Vicario y buscando nuevas expectativas laborales y políticas, fue llamado por Alfredo Rodríguez para incorporarse a la ONG (Espinoza 2015). Desde ahí formó el Taller de Análisis Urbano, que logró articular a más de 12 profesionales y pobladores, para reflexionar, precisamente, sobre este actor social y las potencialidades políticas de los mismos en el contexto dictatorial (Espinoza 2015). Otros en cambio, llegaron a desarrollar pequeños programas - que tenían financiamiento previo- y a los que Sur prestaba apoyo logístico "una casa, un teléfono, oficinas, pero sobre todo un espacio de debate y reflexión" (Saball 2015). De otro lado, algunos intelectuales participaron en Sur a través de los encuentros, escuelas y seminarios que allí se organizaron, teniendo afiliación permanente en otras ONG, como el Programa de Estudios del Trabajo (PET), Grupo de Investigaciones Agrarias (GIA), Programa Interdisciplinario de Investigaciones en Educación (PIIE) o el Centro de Estudios de la Mujer (CEM), lo que daba cuenta de las extensas redes, sin necesidad de una institucionalidad rígida ni formal (Espinoza 2015).

Diferentes experiencias académicas se realizaron en esta ONG. A comienzos de los años 80 se iniciaron las Escuelas de Verano, destinadas a dirigentes estudiantiles, poblacionales y sindicales, y mediante ellas, los intelectuales y profesionales tomaron contacto permanente con los actores sociales en sus propios sitios de habitación y experiencia. Estas Escuelas, que duraban varias sesiones, se encontraban en directa relación con el 
fortalecimiento de los lazos de asociatividad de los sectores populares, fuertemente reprimidos por las fuerzas de seguridad del régimen y duramente golpeados por las reformas neoliberales. En esos encuentros se buscaba conocer las opiniones y experiencias de los propios actores sociales y, a su vez, "ayudar a mover los cercos del temor instalados para avanzar en las dinámicas de rearticulación del movimiento popular" (Espinoza 2015).

Hacia mediados de los años 80 , las múltiples actividades de intervención en el espacio social -financiadas mayoritariamente por agencias europeas y norteamericanas- llevaron a la necesidad de sistematizar el cúmulo de datos, observaciones, impresiones y reflexiones que los trabajos con el mundo popular habían ido produciendo. (http://www.sitiosur.cl/historia. php). En esos mismos años, Sur creó un programa de pobreza, "tendiente a reformular la perspectiva vigente sobre esta realidad"(http:// www.sitiosur.cl/historia.php), a partir de la discusión de los supuestos ideológicos neoliberales que orientaban la política pública desde la Oficina Nacional de Planificación, y de la intervención del espacio social popular mediante fondos para apoyar talleres artesanales, microempresas, casas de la mujer, entre otros.

Por último, una vez que la forma transicional para dar término a la dictadura se encontraba definida por las elites políticas, Sur se volcó de manera "más intensiva a la formación para el desarrollo social" (http://www.sitiosur.cl/historia. php), inaugurando la Escuela de Planificadores Sociales, que buscaba formar a los futuros agentes del desarrollo local en democracia. A diferencia de otras ONG que desaparecieron con el retorno a la democracia en 1990, Sur continuó existiendo. Sin embargo, la primera etapa desarrollada en los 80 tiene una historia distinta de la contemporánea.

\section{La Revista Proposiciones y el campo intelectual de oposición.}

Las Revistas -políticas, científicas 0 de masas- actúan como espacio de asociatividad intelectual, constituyen una expresión de voluntades, de diálogo, de discusión, de debate, de puesta en común. (Munizaga 1984) Articulan cuerpos que -de manera narrativa- reúnen objetivos compartidos que permiten construir y legitimar tanto el sentido como los intereses que persigue, por ello puede ser pensada como una red, a través de la cual se percibe la trama "de lazos de sociabilidad y de intercambios que practican las elites intelectuales entre si, permitiendo visualizar los modos de comunicación y circulación de ideas entre individuos y grupos localizados en diferentes lugares" (Montaña 2013:2). Su unidad intelectual deriva de un proyecto editorial declarado, decisivo a la hora de definir qué, quién y cómo se escribe, por ello su estudio permite ingresar en los contextos de proyectos intelectuales que no poseen estructura ni reglas formales, más que una flexible adscripción a los idearios que se desprenden de los mismos (Devés 2007). Por ello "la única forma de hacer una revista es tener un grupo de personas que tengan las mismas convicciones, los mismos odios; (porque) una colección de textos por autores famosos no produce una revista"(Rocca 2004:14).

La revista política intelectual tiene particularidades referida a sus contenidos y objetivos, pero hay algo que la caracteriza de manera casi intrínseca: "es todo menos un 
medio de masas" (Haacke 1972:73). En efecto, dirigida a un lector específico, aquellos que aspiran a incidir en el espacio de lo público, define lo político y la política desde el campo de la escritura, para instalar formas de nominar la realidad y actuar sobre ella: "[c]orregir y criticar la res pública, reformarla, cuando sea necesario, revolucionarla"(Haacke 1972:103) e instituir los deslindes del campo intelectual político. Como plantea Rocca;

\begin{abstract}
"podrá surgir como expresión de la pobreza de unos jóvenes escritores, podrá emerger con la voluntad de cambiar el mundo con las ideas más radicales que se quiera, pero siempre camina hacia unos pocos, hacia un público de iniciados, casi de cofradía: escritores, artistas, universitarios, profesionales de la cultura, de un mínimo sector de las clases sociales o de los grupos sociales que tienen más vigor, ideológico o económico" (Rocca 2004:7).
\end{abstract}

Lo que en ella cabe y lo que en ella ni siquiera es mencionado, sirve para dibujar sus lineamientos. Así, cuando una "revista elige cuándo, con quién y sobre qué polemizar, está ocupando un lugar central, porque está obedeciendo cuáles son los debates y los interlocutores legítimos" (Patiño, 1997:24). Nunca una amplitud tan diversa que desdibuje su objetivo, sino una diversidad a priori que metaforice el debate y las divergencias posibles, pero jamás antagónicas. Por ello, las revistas son útiles para analizar la circulación de las ideas, así como los modos en que son recepcionadas (Montaña 2013:7), y resultan claves para comprender la sociología de los intelectuales y sus contextos de intervención y debates. En este sentido, juegan un doble papel, constituyen un "lugar de encuentro y sociabilidad" $y$, simultáneamente, operan como un "laboratorio de ideas". (Patiño 1997: 24)

Las revistas político intelectuales actúan y sobreviven en el tiempo de acuerdo a la "fuerza del discurso, el poder de la palabra" (Pecourt 2006:206), la "originalidad de los conceptos y las metáforas presentadas" (Pecourt 2006:206); pero también dependen de sus contextos materiales de producción. La cercanía o lejanía de los poderes políticos, económicos, eclesiásticos o culturales inciden también en su existencia y en la imaginación de su escucha contemporánea. Como indica Bourdieu, "lo que hace el poder de las palabras y de las palabras de orden, poder de mantener el orden o de subvertirlo, es la creencia en la legitimidad de las palabras y de quien las pronuncia, creencia cuya producción no es competencia de las palabras" (Bourdieu 1999:78), o no al menos, de forma exclusiva.

Para el caso de la Revista Proposiciones, el antagonismo con el gobierno militar y los grupos empresariales que detentaban el poder económico, le permitió fijar un locus de enunciación dentro del campo de oposición a la dictadura. Intelectuales jóvenes, mayoritariamente hombres ${ }^{7}$, educados en el mundo universitario durante los sesenta, críticos del marxismo ortodoxo, conscientes de pertenecer a una generación y del lugar que les competía en la transformación social durante la dictadura, les dio una característica particular y también una fuerza a los "actos de habla", de allí que su imagen, su fuerza y su trascendencia se fraguaran en este campo de oposición, del que no fueron los únicos compositores.

Proposiciones publicó en el período 1980 a 1989, con periodicidad variable, diecisiete revistas, según se aprecia en el siguiente cuadro ( $\left.N^{\circ} 1\right)$. De esta información, se observa que en términos estrictamente numéricos, esta revista registra 11 publicaciones antes de

De un total de 140 artículos escritos en Proposiciones, el 84,2\% fueron escritos por hombres y $15,7 \%$ por mujeres. 
1985, mientras para el período 1985 a 1990 solamente 6 apariciones, lo que demuestra, sin entrar en consideraciones sobre el contenido de los repertorios, una mayor producción en la primera etapa. Para efectos analíticos, y luego de identificar momentos en la producción de repertorios de debates de la publicación, se ha subdividido el periodo total en tres momentos, a saber: 1980-1982; 1983-1985; y 1986-1989.

Cuadro $N^{\circ} 1$. Número de revistas Proposiciones publicadas anualmente (1980-1989)

\begin{tabular}{|c|c|c|c|}
\hline Años & № Revistas & Años & № Revistas \\
\hline 1980 & 1 & 1985 & 0 \\
\hline 1981 & 3 & 1986 & 1 \\
\hline 1982 & 3 & 1987 & 2 \\
\hline 1983 & 3 & 1988 & 2 \\
\hline 1984 & 1 & 1989 & 1 \\
\hline
\end{tabular}

Fuente: elaboración propia en base a los datos obtenidos de Proposiciones.

La subdivisión del período de estudio permite visualizar y caracterizar, en primer término, las autorías de los artículos publicados en la revista, distinguiendo entre aquellos que pertenecen a Sur (adscritos) y aquellos que son externos a dicha organización (invitados). Se aprecia en el gráfico 1 un porcentaje decreciente de autores adscritos para el período 1980 a 1989 y la tendencia inversa para el caso de los invitados. Este hecho no resulta accesorio en dos sentidos: por una parte, modifica el ethos de la revista en términos de la composición de sus actores y sus respectivas membresías políticas, sociales e institucionales; por otra parte, al trastocar los niveles de autonomía / heteronomía de la publicación la reubica en el campo de producción simbólica de la oposición a la dictadura. (Mella 2011; Mella 2015)

Gráfico 1: Porcentaje de artículos escritos en Proposiciones por intelectuales de Sur e invitados

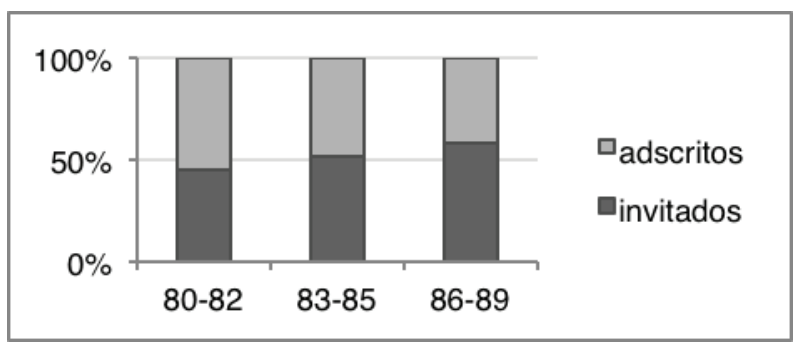

Fuente: elaboración propia en base a los datos obtenidos de Proposiciones.

\section{Producción intelectual de la Revista Prop- osiciones durante los años 80 .}

Para el estudio de la producción intelectual de esta revista se han identificado siete debates predominantes (Ver gráfico 2) durante el período en estudio, buscando clasificar cada uno de los artículos contenidos en Proposiciones en una de estas macro-categorías. (Glaser 1992 y Laperriere 1997). Al respecto, se observa en el gráfico siguiente algunas tendencias principales en la evolución y desplazamientos de los debates contenidos en esta publicación:

i. Desaparición, hacia 1983, de artículos sobre sindicalismo y mundo del trabajo y el debate sobre la categoría de clase, con reaparición hacia el último período, pero inscrito en los debates sobre transformaciones estructurales de la sociedad chilena. 
ii. Disminución drástica de debates, hacia 1985, sobre teoría para la izquierda renovada.

iii. Disminución progresiva de trabajos sobre cultura neoliberal.

iv. Aumento progresivo de debates sobre transformaciones estructurales de la sociedad chilena, centrado en análisis de actores específicos: mujeres, trabajadores, pobladores y jóvenes.

v. Aumento abrupto, desde 1983, de contribuciones sobre democracia y democratización.

Gráfico 2: Porcentaje de artículos según debates centrales registrados en

Proposiciones 1980-1989.

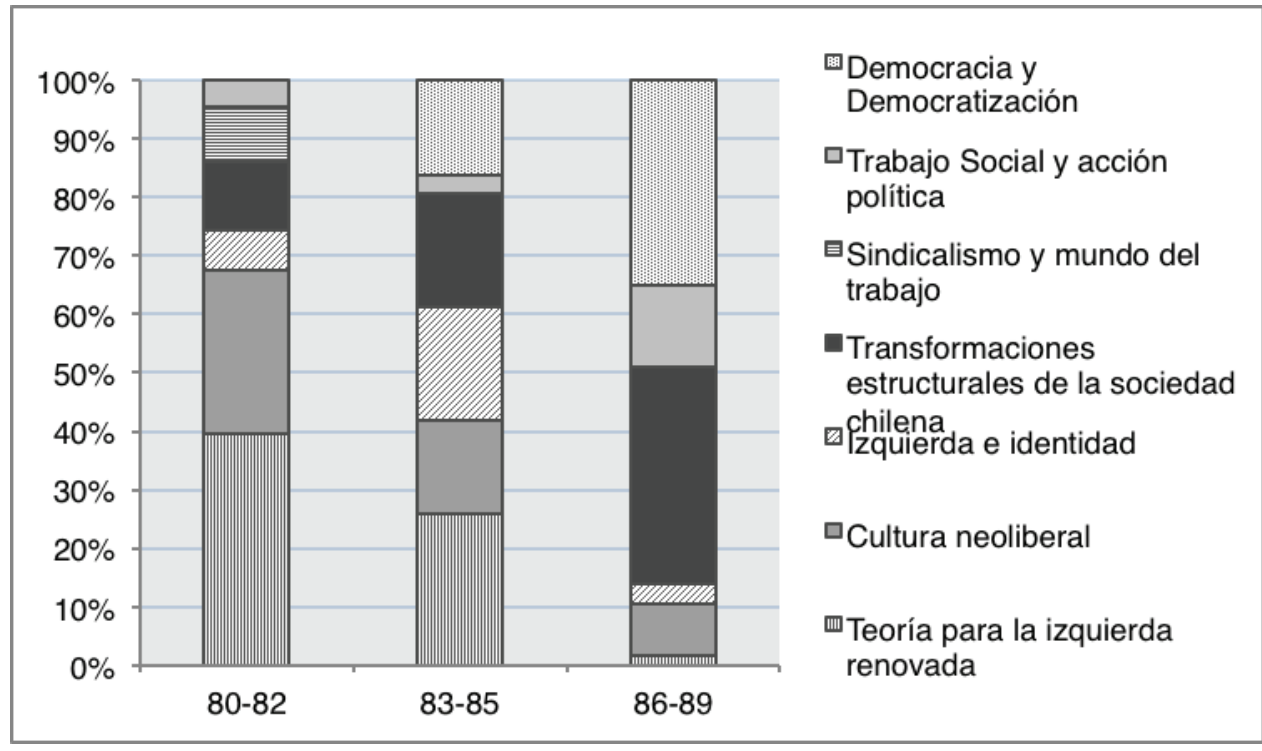

Fuente: Elaboración propia en base a datos obtenidos de Proposiciones 1980-1989 


\subsection{Proposiciones y la delimitación de los debates del campo intelectual de oposición, 1980-1982}

El formato inicial, durante 1980, fue el de un conjunto de artículos que organizaron las discusiones de tres seminarios realizados en Sur: i) "teoría política", dedicado al estudio de temas de la filosofía occidental y que "busca(ba) aportar al desarrollo del debate y a la superación de la crisis teórica que afecta(ba) a los movimientos políticos nacionales"(Proposiciones N¹1 1980:3); ii) "pensamiento social y político chileno", orientado principalmente al "estudio de la trayectoria del pensamiento socialista chileno y de las distintas vertientes políticas en que éste se ha expresado" (Proposiciones Nº1 1980:3); y iii) "estructura económica y social de Chile", dedicado al estudio de "las transformaciones en la estructura productiva, en el empleo, en la estructura de clases, la estructura demográfica y la naturaleza y forma del Estado en el país" (Proposiciones No1 1980:3), con el fin de caracterizar el Chile de ese presente.

Los primeros números tuvieron el carácter de "publicación interna del área de estudios e investigaciones(...) orientada a promover la crítica sobre su labor y a extender la invitación a otros medios intelectuales y profesionales a incorporarse a sus trabajos de seminario" (Proposiciones N¹ 1980, contratapa). Así, desde un comienzo se definió como abierta a la participación y al diálogo con otros actores, en la búsqueda incesante de recomponer un espacio para crear conocimiento y proponer "la reflexión crítica de ungrupo intelectual", que cuestionando el dogmatismo de cualquier especie, rechazara "su coagulación en redacción(es) rígidas o articuladas en extremo". Tal como indicaban en su presentación, lo que allí se proponía era un "conjunto de memoranda para un debate en desarrollo", con la "esperanza de que cada memorándum despierte la discusión, la imaginación, la creatividad; que estimule el parto de un pensamiento nuevo" (Proposiciones N¹ 1980:2). Indicaban que sin proclamar ninguna autoridad a priori, ni verdades indiscutidas, construyeron este espacio para "proponer" a quien "quiera recogerlas, profundizarlas o negarlas" (Proposiciones N¹ 1980:2).

El contenido de los tres seminarios realizados en la ONG, le dieron a la presentación de la Revista un objetivo definido, nacido de tres premisas compartidas en este campo intelectual de oposición vinculado a la izquierda que estaba viviendo un proceso de "renovación" ideológica. En primer lugar, un ajuste de cuentas con el marxismo y la ortodoxia interpretativa; en segundo lugar, el diagnóstico de que la crisis de la Unidad Popular radicó - entre otras causasen la subordinación de los movimientos sociales a los partidos políticos, y, en tercer lugar, la creencia de que la democracia debía ser un valor no transable para la izquierda (Moyano 2011). La crítica al dogmatismo expresada en su editorial correspondió a ese ajuste de cuentas con el pasado reciente; con la forma en que la izquierda había abrazado el marxismo; con la manera en que se había producido conocimiento en los sesenta. Por ello, en el primer número los artículos se concentraron en el debate sobre la "idea de libertad", "notas críticas en torno al análisis histórico tradicional", la caracterización del nuevo estilo de desarrollo capitalista y las transformaciones en la estructura de clases. Escribieron en el primer número inaugural: Javier Martínez, Francisco Javier Vergara ${ }^{8}$,

Historiador, fue militante del MAPU y actualmente es académico de la Universidad Academia de Humanismo Cristiano. 
Justo Mellado ${ }^{9}$, Eduardo Muñoz ${ }^{10}$, Mariana Schkolnik ${ }^{11}$, Eugenio Tironi y Álvaro García ${ }^{12}$.

Hasta el número 9, publicado en el año 1983, la presentación de la revista se mantuvo constante. En la portada un pequeño dibujo de "Libertad" - personaje de Mafalda- mirando hacia el horizonte, marcaba el quiebre con cualquier pasado radical de la izquierda latinoamericana. En la contratapa, la aclaratoria de ser una publicación interna del Área de Estudios e Investigaciones de Sur, con el mismo objetivo de "proponer" y no "establecer".

La dinámica de los seminarios que organizaron los debates se mantuvo con nitidez hasta el número cuatro, momento en el que la publicación incorporó a nuevos intelectuales, artistas y dirigentes políticos. En el cuarto número de la revista, publicado en 1981, escribieron los fundadores Martínez y Tironi, Muñoz y Rodríguez; así como también Paulina Matta Vattier ${ }^{13}$, Carlos Ossandón ${ }^{14}$, Raúl González y Ricardo Solari ${ }^{15}$. Los temas de este número siguieron siendo la libertad, la democracia, el socialismo, pero se le agregaron -de manera narrativa y literaria- preocupaciones por el

Crítico de arte, fue militante del MAPU y ha sido director de la Escuela de Arte de la Pontificia Universidad Católica de Chile y de la Escuela de Artes Visuales y Fotografía de la Universidad UNIACC.

10 Historiador

11 Economista, vinculada al PET, más tarde fue directora del Instituto Nacional de Estadísticas en el año 2008.

12 Economista, fue militante del MAPU y Ministro de economía entre 1994 y 1998

13 Artista gráfica que asume las labores de diagramación de la revista y que escribe un artículo sobre el poeta Pablo Neruda.

14 Filósofo, Doctor en Filosofía por la Universidad de Gante, Bélgica.

15 Ingeniero comercial con mención en Economía, dirigente político del Partido Socialista Almeyda en clandestinidad. sentido de la historia, la identidad nacional y por cierto, los cambios profundos que la sociedad chilena experimentaba. Consumismo, disolución e individualismo poblaron los textos, como preocupación filosófica y política (Ver gráfico 2).

Entre el número 5 y el número 9, los cambios son evidentes y fueron dando cuenta de la articulación de los límites - externos e internosdel campo intelectual de la oposición política en Chile. Si bien la mantención de la portada y los objetivos de la publicación siguieron sin modificación, el quinto número abrió la estructura argumentativa y los temas se diversificaron. La preocupación por los sujetos sociales desbordó las páginas (Ver gráfico 2). Así junto a la preocupación por la clase obrera y el interés por el sindicalismo, también irrumpieron los pobladores y las mujeres. En 1982, meses antes que la crisis económica hiciera su entrada triunfal en el debate de la coyuntura, escribieron sobre trabajadores y los cambios en el mundo sindical, así como sobre la pertinencia de la categoría de "clase": Patricio Castro" ${ }^{16}$, Mario Alburquerque ${ }^{17}$, José Bengoa y Eugenio Tironi. Complementaron ese número el artículo de Vicente Espinoza $^{18}$ dedicado al movimiento de pobladores y el de María Teresa Marshall ${ }^{19}$ que reflexionaba sobre el trabajo social en el espacio territorial de la población. Junto a ellos, el texto de Andrea Rodó ${ }^{0}$ que abordó a la mujer

16 Economista

17 Sociólogo, también militante del MAPU, con estudios en la Escuela de Altos Estudios en Ciencias Sociales (EHESS) y de gestión de calidad en la JICA, Japón.

18 Sociólogo, fue militante del MAPU y actual académico del Instituto de Estudios Avanzados de la Universidad de Santiago de Chile.

19 Trabajadora Social de la PUC, magister en sociología y experta en temas de educación. También militó en el MAPU.

20 Estudió trabajo social y posteriormente sicología. Militó en el MIR y se encuentra casada con Eugenio Tironi. 
pobladora y su sexualidad, vinculó el debate feminista a las páginas de Proposiciones.

El número 6 recuperó con fuerza el debate filosófico para la izquierda. Aparecieron nuevos autores, como Luis Razeto ${ }^{21}$, Pasquale Misuraca $^{22}$, Franz Hinkelammert ${ }^{23}$, Carlos Ruiz ${ }^{24}$, Alfredo Riquelme ${ }^{25}$ y Eduardo Valenzuela ${ }^{26}$, quienes reflexionaron sobre el dogmatismo, epistemología de las ciencias y filosofía de la historia. Dicho número contenía los materiales del seminario "Para una nueva política" organizado por Sur en 1981 y que buscó reflexionar sobre "los requisitos de un sujeto colectivo capaz de representar adecuadamente esa propuesta alternativa, así como el carácter y las raíces históricas de los fines de un movimiento de esa especie"(Proposiciones Nํ6 1982:7). Allí se recogieron reflexiones ya dichas, para ir delimitando el campo de la discusión, fijando los temas y los saberes que circulaban. Tal como expresaba Javier Martínez, director académico de Sur en esos años, ese número estaba hecho para "dejar huella" (Proposiciones Nº6 1982:8), porque "deja constancia de una ruptura con los viejos conceptos" (Proposiciones N6 1982:9) a partir de los cuales "observar desde afuera un pensamiento que nos recorre sin dejar conciencia clara de sus bordes" (Proposiciones No6 1982: 9).

\footnotetext{
$21 \quad$ Licenciado en Filosofía y Magister en Sociología. Fue militante del Partido Comunista.

22 Escritor, sociólogo y guionista de cine.

23 Economista y teólogo alemán, uno de los exponentes de la teología de la liberación.

24 Filósofo.

25 Historiador, militó en el Partido Comunista.

26 Historiador experto en estudios sobre movimiento estudiantil.
}

Por ello se compilaron textos heterogéneos, "tanto desde el punto de vista temático como de su preparación previa" en algunos casos eran planteamientos derivados de investigaciones concluidas o en curso" (Ibíd:8), en otros, "reflexiones de carácter más bien especulativo o aproximaciones a un punto de partida desde el cual abordar determinados problemas"(Ibíd:8). Sin embargo, reunidos daban cuenta del "estado de la reflexión de un círculo de intelectuales en un momento preciso del desarrollo histórico nacional", que aportaban claves para la "comprensión de una coyuntura teórica en el seno de la intelectualidad crítica; y a partir de ello, para la captación de los terrenos de oscuridad o ambigüedad en que el pensamiento aparec(ía) comprometido" (Proposiciones N6 1982:8). De allí que hacia el final de la presentación de Martínez se hiciera un rescate de la autoría. La valoración del "nombre del autor", que para estos intelectuales equivalía "a pronunciar la confesión de una disidencia". Equivalía a decir: "Nosotros fuimos" (Proposiciones Nº6 1982:10).

En 1982, el campo intelectual de oposición que delineaba un sector de la izquierda nacional, en particular, quienes compartían las premisas previamente indicadas y que tradicionalmente han sido nominados como "renovados", quedaban con sus marcos enunciados y declarados (Ver gráfico 2).

\subsection{Proposiciones y los desbordes contenidos. 1982-1986.}

El número 7 de 1982 dio cuenta de la importancia de la coyuntura para este mundo intelectual. La grave crisis económica que comenzaba a mostrar sus primeras señales, golpeaba con fuerza al mundo popular y generaba expectativas de un fin próximo de la Dictadura, abriendo desafíos 
analíticos que nacían del reconocimiento de la necesidad de consolidar una matriz teórica para pensar el presente y el futuro. La revista se planteaba como objetivo inmediato

\begin{abstract}
"abrir el debate teórico frente a algunos de los temas que, pertenecientes a la humanidad entera, permanecieron por largo tiempo anquilosados en la conciencia progresista hasta que el radicalismo neoliberal volvió a enarbolarlos con limpieza; en particular, el reclamo por más sociedad y menos Estado y por una conformación de la voluntad colectiva a partir de un mecanismo "automático" (el mercado) que evite la interferencia de un intérpretedéspota"(Proposiciones No7 1982:9).
\end{abstract}

Tironi se planteaba la necesidad de buscar en el neoliberalismo algunas claves para repensar el socialismo, Razeto se abocaba a un ejercicio analítico para comprender el mercado, las recesiones y los ajustes automáticos. Bengoa cuestionaba al historiador conservador Mario Góngora y su "noción de Estado en Chile" y Alfredo Rodríguez entregaba claves para "pensar en una ciudad democrática". Intelectuales de Sur e invitados de otras ONG, comenzaron a ocupar un lenguaje donde las categorías analíticas de modernización y democracia caminaban juntas y sin conflictos.

Mujeres, ollas comunes, experiencias de intervención social y reflexiones sobre los actores en sus espacios territoriales, poblaron también las páginas de este número, en donde aparecieron las primeras imágenes a cargo de la artista Paulina Matta. Estos textos a cargo del Colectivo de Trabajadoras Sociales, del que formaron parte Paulina Saball, Daniela Sanchez, Ana María Medioli y Ana María de la Jara27, dieron cuenta de la valoración del conocimiento social reflexivo surgido de la práctica. Tal como recuerda Saball, "nos nació la necesidad de vincular el trabajo social con la reflexión metodológica, que rápidamente encontró eco en la discusión sobre educación popular y los actores sociales. Fue el mismo momento en que Sur se empezó a abrir a la reflexión del tema de los jóvenes, de los pobladores, de las mujeres..." (Saball 2015).

Así, junto a la reflexión teórica más clásica, la revista también daba cuenta de la existencia de una forma de generar conocimiento que valorizaba la práctica de intervención social como eje constitutivo de los cambios sociales y los actores. Según Saball (2015) estas dos formas convivieron armónicamente porque existieron intelectuales que hicieron de puente: "Por ejemplo, "Pepe" Bengoa, que si bien era bastante teórico para sus reflexiones, también tenía una vasta experiencia en temas de educación popular y con la gestión del mundo campesino". Así, experiencias formativas previas, junto a las dinámicas políticas de "intervenir en la emergencia" después del Golpe, caracterizaron a este grupo diverso de intelectuales que convergieron en Proposiciones.

La última revista con el mismo formato inicial se publicó en 1983. El número 8 de la Revista Proposiciones junto con integrar nuevos autores, como Germán Bravo, Alejandro Jara y Justo Mellado -quienes de forma literaria se abocaron a delinear los límites imaginarios de la izquierda renovada- daba cuenta del debate contenido al interior de dicho campo intelectual.

Las protestas populares de 1983 fueron el telón de fondo de una discusión que se movió entre dos límites. Por un lado, las posturas encabezadas por Tironi, para quien la izquierda debía abandonar la idea de que "todo era político", porque aquello conducía a 
la "ineptitud en la actividad política concreta y traduce sin pensarlo una visión reductivista, totalitaria, del hombre y la sociedad...." De allí que la principal renovación sea simplemente "aceptarlo". (Proposiciones N8 1983:10). Por otro lado, estaban aquellos que veían en la acción de los sujetos populares una posibilidad de transgresión al modelo neoliberal. Pequeñas prácticas cotidianas que, marcadas por las nuevas dinámicas de asociatividad, producirían la posibilidad de ruptura que obligaría al régimen militar a permitir el llamado a elecciones libres. Ya que la política podía ser también

\footnotetext{
"negatividad: crítica del Estado y de las formas de dominación que se ejercen sobre la sociedad. En cuanto tal la pregunta por su eficacia es cuando menos insignificante. La extensión de la política, en la forma cómo se manifiesta en estos días, tiene precisamente esa dirección antiestatalista, "antiimperialista" según la terminología empleada: en ese sentido, constituye un signo de renovación que merece ser tomado en cuenta y justipreciado en todo su valor" (Proposiciones No8 1983:36).
}

Las tensiones internas del campo intelectual marcaron el derrotero de los siguientes números y el campo de expresión fue precisamente el debate sobre los "actores sociales" y su futuro en la democracia por venir.

Proposiciones 9 cambió su formato de edición. Cinco líneas rectas en dirección horizontal, con la primera de ellas en color, seguían al título, delineando un tono mucho más académico y experto, que re-presentada como "libro editado por el Programa de Estudios Políticos de Sur", mantenía el objetivo de ser un espacio para la reflexión crítica y anti dogmática.

La mantención de su numeración mostraba su continuidad en el campo intelectual que buscaba interpretar, aunque su formato y presentación expresaban los cambios que se producían al interior de la izquierda renovada. Los nuevos números, hasta el 11, presentaron una estructura interna distinta, ya que se diferenciaban "Artículos" de "Documentos" y comenzaron a aparecer autores extranjeros como Judith Astelarra y Rose Cheetman, Elizabeth Jelin, o exiliados chilenos cuya obra era importante revincular a Chile, como el caso de Walter Hoefler, residente en Darmstadt, Alemania Federal. Dichos autores eran presentados al público lector con una breve biografía y la referencia del origen de la publicación que ahí se reseñaba.

Los textos mantenían el carácter heterogéneo dentro de un campo en tensión contenida. Filosofía, historia, mundo popular, mujeres, jóvenes y pobladores van compartiendo un espacio, donde la discusión evidente va introduciendo un "sentido común" político que cruza todo el campo: la preocupación por la democracia y la definición de la democratización.

Junto a lo anterior la revista va incorporando nuevos intelectuales. Es el turno de compartir espacios entre viejos autores como Aníbal Pinto y los emergentes Eduardo Devés ${ }^{28}$, Rolf Foerster $^{29}$, Pedro Güell ${ }^{30}$, Manual Antonio Garretón ${ }^{31}$, Gabriel Salazar ${ }^{32}$, Alex Rosenfeld ${ }^{33}$ y Olga Segovia ${ }^{34}$, por mencionar a algunos.

28 Historiador, ex militante del MAPU, actual académico del Instituto de Estudios Avanzados.

29 Antropólogo, actual académico de la Universidad de Chile.

30 Sociólogo, doctor en sociología por la Universidad de Erlangen Nümberg, Alemania

31 Sociólogo y Doctorado de L'Ecole des Hautes Etudes en Sciences Sociales, Paris. Premio Nacional de Ciencias Sociales en 2007.

32 Historiador, realizó estudios en filosofía y sicología y se doctoró en Historia Económica y Social en la Universidad de Hull, Inglaterra. Premio Nacional de Historia 2006.

33 Historiador.

34 Cientista social experta en temas de ciudad, violencia y género. 
Durante el año 1985 no se publicó la revista y en 1986, con la aparición del número 12, la edición tomó un giro que se mantiene hasta la actualidad. El mismo año decisivo, cruzado por la derrota de la vía insurreccional a la dictadura - tras el fallido atentado al General Pinochet -, Proposiciones cambió su estilo, forma y contenidos -de apariencia muy diversos-, articulados por una forma compartida de pensar la democracia, la sociedad, la política y el conocimiento. En conjunto con ellos, la llegada de intelectuales que habían estado en el exilio, como Gabriel Salazar, o la partida de intelectuales relevantes de la primera etapa, como Vicente Espinoza -en 1986-, para realizar estudios doctorales fuera de Chile, fueron ejemplo del giro político, social y cultural en las formas de generar conocimiento (Espinoza 2015).

\subsection{Proposiciones para los nuevos tiempos: 1986-1989.}

En el nuevo formato se indicaba, por primera vez, la fuente de financiamiento -SAREC, Agencia Sueca para la Cooperación y la Investigación-, la inscripción en el registro de propiedad intelectual, un editor responsable, la editorial en donde se realizaba la impresión y el lugar de venta de la misma. Hacia 1986, Proposiciones había dejado de ser la publicación hecha a mimeógrafo y distribuida en "talleres", "encuentros" y que llegaba al extranjero, "probablemente a través de un esténcil" (Espinoza 2015), por las redes de los intelectuales chilenos y que en el interior se repartía semi clandestinamente en las universidades nacionales (Espinoza 2015).

Desde el número 12 en adelante, la revista estuvo estructurada por una editorial que presentaba el número y un conjunto de artículos - de distintos temas que daban cuenta de las preocupaciones del campo intelectual-, notas, reseñas de libros y documentos. Cada uno de los acápites dio cuenta de la diversidad de formatos de comunicación del saber producido. Pobladores, poder local, indígenas, militancias y experiencias de asociatividad popular, convivieron con textos de teoría sociológica y ensayos transitológicos e historiografía, mostrando la diversidad y complejidad que había ido adquiriendo el campo intelectual de oposición en las postrimerías de los años 80. El debate sobre los actores sociales tomó relevancia, pero cruzado por una mayor intensidad de las tensiones indicadas en el período anterior.

En el número 13 de 1987 aparecieron publicados los integrantes del comité editorial conformado por José Bengoa, Javier Martínez y Eugenio Tironi. A su vez, se distinguieron la sección "notas" de los "informes de investigación", los cuales alcanzaron mayor relevancia dentro de la propia revista. Aumentaron las reseñas de libros, que daban cuenta de las prácticas de lectura de estos intelectuales, que mediante presentaciones criticas proponían qué y a quién leer. La mayoría de los textos reseñados referían a autores nacionales, vinculados a otras ONG y centros de estudios, como CEPAL, FLACSO y CIEPLAN. Los intelectuales de Sur recomendaban leer a Dagmar Racynzki ${ }^{35}$, José Pablo Arellano ${ }^{36}$, Manfred Max Neef ${ }^{37}$, Oscar Muñoz ${ }^{38}$, Sergio Bitar ${ }^{39}$ y Crisóstomo

35 Doctora en Sociología por la Universidad de California, académica de la Universidad Católica de Chile. Trabajó en CIEPLAN en los años 80 .

36 Economista, militante de la Democracia Cristiana. Durante los años 80 trabajó en CIEPLAN. En el 2006 fue presidente de CODELCO.

37 Economista, ambientalista y político chileno. Fue candidato a la presidencia en 1994. Durante su exilio trabajó en Argentina en la Fundación Bariloche.

38 Economista, durante los años 80 trabajó en CIEPLAN.

39 Ingeniero, ministro de los Presidentes Allende, Lagos y Bachelet. 
Pizarro $^{40}$, Eda Gaviola ${ }^{41}$, José Joaquín Brunner ${ }^{42}$ y Bernardo Subercaseaux ${ }^{43}$. La editorial del número configuraba un discurso aglutinador de las preocupaciones de 1987, en los que los intelectuales referenciados -más los articulistas frecuentes de la revista- orientaban sus disquisiciones. La proximidad de un plebiscito y la posibilidad de una salida pactada con la dictadura habría los debates sobre la sociedad futura, nacida de un presente en el que

\begin{abstract}
"La exclusión y la pobreza se han ido constituyendo en nosotros como una obsesión intelectual. En la sociedad chilena existen seguramente muchos problemas, pero no nos cabe duda de que éste es el mayor. ...En la base de las dificultades para transitar a la democracia se encuentra la miseria de muchos, la pobreza de esta mayoría está en la ciudad, en la otra ciudad" (Proposiciones №13 1987:9).
\end{abstract}

Les preocupaba profundamente que el nuevo sujeto, nacido de las políticas represivas y la instalación del neoliberalismo, pudiera ser verdadero actor ciudadano. Para algunos de ellos resultaba alarmante que "el populismo en la relaciones con el Estado, el poder y la autoridad es lo que los ha marcado, y lo que aún permanece"(Proposiciones №13 1987:10). Mantenían eso sí, alguna confianza en que

\begin{abstract}
"la comunidad, el grupo, el taller de subsistencia, el comprando juntos, y tantas iniciativas, van ejemplificando la solidaridad de los pobres, signo positivo, expresión de la resistencia a dejarse destruir y elemento necesario de considerar en la construcción de una sociedad en que no sólo los bienes estén mejor repartidos, sino también los valores y la convivencia sean mejores" (Proposiciones No13 1987:11).
\end{abstract}

Historiador, trabajó en CIEPLAN y en la UNICEF

41 Historiadora feminista vinculada a la ONG La Morada.

42 Con estudios en sociología, fue director de FLACSO entre 1976 y 1984, militó en el MAPU y fue ministro Secretario General de Gobierno entre 1994 y 1998.

43 Literato e historiador, especialista en historia de la cultura. Actual académico de la Universidad de Chile.
La edición del $N^{\circ} 14$ en el mismo año 87 representó otro cambio significativo. Bajo el título central apareció por primera vez un subtítulo, que daba cuenta del tema que aglutinaba los artículos. Este número se subtituló "Marginalidad, Movimientos sociales y Democracia". También cambió su presentación en la que se indicaba que correspondía a una "colección de ediciones Sur", publicada tres veces al año y que "recoge los principales resultados de las investigaciones que realiza el Centro de Estudios Sociales y Educación Sur, y artículos que reflejen los debates en curso en el campo de las ciencias sociales" (Proposiciones No14 1987:1). Paralelo a ello se planteó que era función del consejo editorial la selección de los trabajos y que no necesariamente se correspondían con la opinión de los editores ni de Sur. Así, la famosa consigna de la memoranda para el debate y el "nosotros fuimos" de Martínez, donde el escribir era sinónimo de la posición política del intelectual, se diluía en una propuesta que se orientaba hacia la comunicación académica más tradicional.

El nuevo número se parecía más a una revista de expertos. Congregaba las exposiciones realizadas en el Seminario Movimientos Sociales urbano-populares y procesos de democratización, realizado en Santiago en abril de 1987, financiado por CADIS (Centre d'Analyse et d 'Itervention Sociologique) dirigido por Alain Touraine, más el apoyo del gobierno francés y de CLACSO ${ }^{44}$. Allí escribieron los ya frecuentes Tironi y Rodríguez, así como el columnista del PET, Luis Razeto, pero también aparecieron los nombres de nuevos autores

\footnotetext{
Particularmente el proyecto encabezado por Fernando Calderón "Sistemas políticos y el fenómeno de las democracias emergentes en Sudamérica", financiado por CLACSO y que formaba parte del Programa PAL (Perspectivas de América Latina), coordinado por Pablo González Casanova.
} 
como Víctor Tokman (PREALC,Chile), Bryan Roberts (Universidad de Texas, USA) Francois Dubet (CADIS, Francia), Guillermo Rosembluth (CEPAL, Chile) Clarisa Hardy (PET), Francisco León (ILDES-CEPAL, Chile) Manuel Antonio Garretón (FLACSO, Chile), Guillermo Campero (ILET, Chile), René Mayorga (CERES, Bolivia), Elizabeth Jelin (CEDES, Argentina), Alejandro Foxley (CIEPLAN, Chile), Ernesto Tironi (CED, Chile), Fernando Calderón (CLACSO, Argentina), Cristian Parker (CERC, Chile), Lucio Kowarick (CEDEC, Brasil), Miguel Lawner (ICAL, Chile), Gonzalo Falabella (SUR, Chile) y el mismo Alain Touraine (CADIS, Francia), que cierra el número con una interesante conclusión:

\begin{abstract}
"Me llamó la atención el tono pesimista-o para emplear una palabra que fue utilizada varias veces- "desesperanzado" (se habló a veces de "optimismo catastrófico" o "pesimismo alentador", pero siempre fue el mismo clima). Esto me parece importante y positivo. Muchas veces en los estudios sociológicos, especialmente latinoamericanos, hay un tipo de prejuicio optimista: se forman actores que liberan las sociedades, hay crecimiento económico, etc. ...Tal vez no se trata de saber si la historia va a ir en tal o cual dirección, sino de saber si estamos bien equipados, cómo están nuestras herramientas, nuestras maquinarias" (Proposiciones Nº14 1987:216).
\end{abstract}

En otras palabras, el rol del intelectual, para el sociólogo francés, era hacer inteligible la realidad social, "nosotros somos los que tenemos que analizar, discutir conceptos, elaborar pautas de análisis" (Proposiciones N¹4 1987:216). La fuerza del intelectual experto quedó sancionada en esa frase, revelando la tónica que tomaba el campo intelectual y que era consecuente con el perfil de las instituciones convocadas a la discusión. Desaparecieron los actores sociales en diálogo directo con los intelectuales, predominaron las encuestas, el enfoque con tono neutral, el sesgo academicista. Se tomó distancia de la realidad intervenida. El llamado a establecer un vínculo permanente con los sujetos sociales, para colaborar a su emancipación y empoderamiento, se deshizo rápidamente mientras se avanzaba hacia el retorno democrático. Proposiciones demostraba no ser sólo reflejo de estos cambios, sino que también factor de su propia constitución. Los nuevos intelectuales y sus redes, sus repertorios y sus formas de generar conocimiento, delineaban el nuevo campo intelectual.

En paralelo con ello se visibilizaron las redes intelectuales internacionales y los temas de preocupación que se compartieron con otros actores. Los procesos de democratización iniciados en 1983, tenían ya un quinquenio de existencia y un conjunto de debates en el que confluían conceptos, preocupaciones y enfoques. La presencia de intelectuales del CEDES y CLACSO de Argentina, del CEDEC de Brasil o del CERES en Bolivia, fue un ejemplo de esa red intelectual conosureña.

Los últimos números de esta etapa mantuvieron el giro de 1987. El número 15 dedicado a reflexionar sobre la educación popular y sus aportes a la transformación de los sujetos, tuvo un tono crítico y expresaba cierta tensión entre los autores. Los primeros artículos aglutinados bajo el encabezado de "Visión crítica de la educación popular", estuvieron a cargo de José Bengoa, Javier Martínez, Guillermo Labarca, Isidoro Cheresky y Franz Hinkelammert. La posición disidente la estructuraban los artículos históricos en manos de Gabriel Salazar y Alfredo Riquelme, así como la recuperación de las experiencias de intervención social a cargo de Andrea Rodó y Paulina Saball.

Así, mientras Bengoa indicaba que "la no dilucidación de la tensión entre educación y política ha conducido a muchos programas a 
la crisis, ya sea por la adscripción irreflexiva de sus participantes a una opción política externa, o por el refugio de los mismos en una práctica comunitaria autoreferida" (Proposiciones Nº15 1987:21); Saball y Rodó valorizaban la experiencia de la educación popular como un aporte sustantivo a la constitución de sujetos en actores. Para las mujeres, enfatizaban, estas experiencias les permitieron pasar "de un rol de mero acompañante de las iniciativas que intentaban hacer frente a la emergencia, a constituir un factor clave frente al desafío de llegar a construir un movimiento de mujeres con identidad, demandas y propuestas propias" (Proposiciones №15 1987:194), por ello, era clave mantener esas prácticas en los espacios poblacionales y al intelectual vinculado a la reflexión dialógica con los sujetos. Estas tensiones, que implicaron decisiones vivenciales, cruzaron a todo el espectro de intelectuales del mundo de las ONG, tanto al interior como entre ellas mismas. ${ }^{45}$

\section{El número 15 de Proposiciones también} permitió pesquisar el debate político al interior de los intelectuales de la izquierda renovada. Su preocupación por los actores sociales seguía siendo relevante, pero con otro cariz y otra orientación. Para varios de ellos, los sujetos populares surgidos al alero de las transformaciones sociales y económicas de la dictadura, carecían de las herramientas para transformarse en futuros actores políticos y ciudadanos. La reaparición del concepto de

\footnotetext{
Ejemplos de estos debates y tensiones fueron plasmados en la publicación hecha por la ONG ECO con motivo de la conmemoración de sus 30 años de existencia, en particular los textos titulados en "Las Trancas: Análisis de tres coyunturas significativas y las cuestiones estratégicas, 1983-1989" y "ECO en el horizonte latinoamericano: La educación popular bajo la dictadura". Disponibles en http://www.ongeco.cl/coleccioneditorial-eco-30-anos/
}

marginalidad social no fue casual, aunque ya no tenía el toque integrador al que apeló Vekemans, sino que cuestionaba las posibilidades reales de fundar una democracia con democratización conjunta y simultánea.

En ese escenario -quizás-, las elites eran las únicas que podían conducir el proceso. Las cercanías entre Sur, CIEPLAN (de orientación Demócrata Cristiana (DC)), el CERC y el CED (también de orientación DC), estaban dando cuenta de las convergencias políticas pero también ideológicas que había alcanzado el campo intelectual de oposición en las postrimerías de los 80 .

El número 16, marcado por la coyuntura plebiscitaria y publicado en 1988, se tituló "Plebiscito y Elecciones". Los autores reflexionaron sobre qué se ganaba con el plebiscito, quiénes decidirán en las elecciones, quiénes históricamente han perdido en los procesos eleccionarios, así como visiones sectoriales sobre la futura democracia: jóvenes, mujeres, empresarios y trabajadores, articularon reflexiones sobre los diferentes impactos que la cercana elección pudiera traer consigo. Planteaba su editorial que este número se dedicaba a entregar antecedentes sobre el contexto en que se produciría el plebiscito,

\footnotetext{
"Muchos de ellos son producto de investigaciones recientes, que han tenido como objetivo sondear el estado de la sociedad chilena. No son datos para decir si va a ganar o perder el gobierno o la oposición. Son cifras que muestran el difícil parto plebiscitario; la incredulidad de muchos sectores; las dificultades de provocar, en torno a esta mecánica electoral, una movilización efectiva de intereses" (Proposiciones Nº16 1988:10).
}

El último número de esta etapa correspondió al 17, editado en 1989. Allí se abandonó la preocupación electoral y volvieron los temas 
sectoriales. Dedicada en su conjunto al mundo del trabajo, los dilemas del sindicalismo y la comparación con otros espacios nacionales, se analizaban los conflictos que los trabajadores enfrentaríanenlanuevasociedad, probablemente democrática. El tono fue pesimista, ya que los enclaves autoritarios en la legislación laboral y las transformaciones en la asociatividad de los trabajadores, auguraban que este actor no sería central en las futuras transformaciones sociales. Las preguntas quedaban abiertas, el futuro se dibujaba oscuro. La transición anunciaba sus límites y estos intelectuales, sin denunciar, relataban el "verdadero estado de la cuestión". El tono neutral teñido de escepticismo, el manejo de datos derivados de encuestas, las series estadísticas que mostraban un deterioro significativo de la importancia relativa de los trabajadores asalariados, preocupaban "científicamente" al mismo grupo de intelectuales que en los inicios de la publicación se preguntaban por la pertinencia de la categoría de clase. En 1989, la clase había desparecido del lenguaje y probablemente también de los proyectos políticos. Proposiciones, como expresión del campo intelectual de oposición durante los años ochenta también llegaba al fin de una etapa.

\section{Conclusión.}

En 1989 se cerraba una historia iniciada en 1980, marcada por el surgimiento y transformación del campo intelectual de oposición. De la necesidad de comprender la realidad para colaborar al dialogo con los actores sociales y la transformación de su cotidianeidad, donde el saber y la política caminaron de la mano sin tensiones, el campo se reorientó hacia la experticia. Neutrales, con nuevos grados académicos, nuevas formas de comunicación científica y nuevas redes intelectuales, la Revista Proposiciones resulta un buen ejemplo para mirar las continuidades, las rupturas y las transformaciones de aquellos actores que asumieron el saber sobre lo social, primero: como objetivo político declarado para hacer oposición a la Dictadura y posteriormente: como saber experto para aportar a la comprensión de la realidad. Otros debían transformarla. Quizás el Estado y las elites, porque el "horno no estaba para bollos". Los nuevos sujetos de la era neoliberal eran dudosos portadores de ciudadanía y la revista daba cuenta de ese debate, cargado del pesimismo que reconocía, como positivo, el sociólogo Alain Touraine.

El estudio de esta revista también nos permitió revisitar un campo intelectual abierto al diálogo con otros sujetos intelectuales, un espacio de divergencias y gran actividad productiva de saberes, pese a las numerosas restricciones de la dictadura. La revista Proposiciones nos permitió demostrar cuan conectados estaban los debates sobre actores sociales, democracia y democratización que circulaban en el cono Sur y en Europa, con los producidos al interior del país, así como también la imbricada red de relaciones entre los múltiples centros creadores de conocimiento.

Los puntos de convergencia es algo que todavía puedeseguirestudiándose, porque seguramente fueron encuentros marcados por tensiones, por posiciones y por redes que fueron tomando direcciones divergentes conforme se articulaba el primer gobierno democrático que asumió el 11 de marzo de 1990 y del que formaron parte varios articulistas de esta importante revista. Esa es una historia de continuidades que queda como desafío pendiente. 
Lo que si podemos afirmar al cierre de este artículo, es que la Revista Proposiciones no sólo fue un reflejo de los debates del campo intelectual de oposición, sino que también actuó como factor del mismo, abriendo sus páginas a ciertos repertorios y a ciertos actores, configurando un universo intelectual donde circularon actores nacionales e internacionales, donde se pusieron en circulación "sentidos comunes" sobre la democracia y la democratización y en que el se abrió la izquierda renovada al diálogo con el centro demócrata cristiano. Por último, la revista también fue un indicador de las mutaciones en la generación y difusión del conocimiento, así como de las transformaciones en las prácticas de asociatividad intelectual y las conexiones con las formas académicas aceptadas de publicar el "saber" experto.

\section{Bibliografía}

Agurto, I.1988. "Las organizaciones No Gubernamentales de Promoción y Desarrollo Urbano en Chile. Una propuesta de investigación". Material de Discusión $N^{\circ} 110$. Santiago de Chile. FLACSO

Bastias, M. 2013. Sociedad civil en dictadura. Relaciones transnacionales, organizaciones y socialización política en Chile. Santiago. Ed. Universidad Alberto Hurtado.

Beigel, F. 2013. "Centros y periferias en la circulación internacional del conocimiento". Revista Nueva Sociedad, Nº 245,:110-123,

Bourdieu,P.1999. Intelectuales, política y poder. Buenos Aires. Eudeba.

Brunner, J.J. 1985. "La participación de los Centros Académicos Privados en Chile" Revista de Estudios Públicos. N ${ }^{\circ}$ 19: 1-12.

Devés,E. 2003. El pensamiento latinoamericano en el siglo XX. Tomo II. Desde la CEPAL al neoliberalismo (1950-1990). Santiago de Chile.

Devés, E. 2007. Redes intelectuales en América Latina. Hacia la constitución de una comunidad intelectual. Santiago de Chile. Editorial IDEA-USACH.

Eloy, H.2014. Revistas y publicaciones literarias en Dictadura (1973-1990).Santiago. Piso Diez Ediciones.

Espinoza, V. 2015. Entrevista.

Garcés, M. 2010. "ECO, las ONGs y la lucha contra la dictadura militar en Chile. Entre lo académico y lo militante". Revista Izquierdas, vol3. N07:1-8.

Garcés, M. 2015. Entrevista.

Garretón, M. 2014. Las ciencias sociales en la trama de Chile y América Latina, Lom, Santiago de Chile.

Glaser, B. 1992. . Basics of grounded theory analysis. Sociology Press, Mill Valley.

Haacke,W. 1972. "Historia intelectual, cultural y social de la revista política" en Revista Española de la opinión pública. №28, abril-junio 1972: 71-105.
Iglesias, M. 2015. "Lo social y lo político en Chile: itinerario de un desencuentro teórico y práctico". Revista Izquierdas. № 22 : 227-250.

Jocelyn Holt, A. 2000. "Sociedad civil y organizaciones no gubernamentales en Chile: una historia germinal. Ponencia presentada en Congreso Nacional de ONG, Picarquín. s/p.

Laperriere, A. 1997. "La théorisation ancrée ("grounded theory"): démarches analytiques et comparaison avec d'autres approaches apparentées". La recherche qualitative: enjeux épistémologiques et méthodologiques. Gatean Morin Éditeur, Boucherville.

Lozoya, I. 2015. Pensar la revolución, intelectuales y pensamiento latinoamericano en el MIR chileno, 1965-1973, Tesis Doctoral en Estudios Americanos. Universidad de Santiago de Chile.

Mella, M (comp.). 2011. Extraños en la noche. Intelectuales y usos políticos del conocimiento durante la transición chilena. Santiago de Chile. Ril editores.

2015.. "Marxismo-Leninismo, pensamiento iconoclasta y nuevo sentido común socialista en Chile durante la década de 1980". Revista Izquierdas: 57-81.

2011. "Referentes internacionales para el giro reformista de la izquierda chilena (1975-1990)". Espacios Públicos, Enero-Abril, 155-175.

Montaña, J. 2013. "Reconstruir la trama democrática en América Latina: el papel de revistas y centros de investigación en la dinámica de renovación intelectual (1970-1980).En Acta Académica.

http://www.aacademica.com/000-038/445_consultado noviembre del 2015.

Moyano, C. 2011. "Pensar la transición a la democracia. Temas y análisis de los intelectuales MAPU en SUR y FLACSO, 1976-1989", en Mella, M(comp) Extraños en la noche: intelectuales y usos políticos del conocimiento durante la transición chilena. Santiago de Chile. RIL editores.

.2009. "Los líderes de la izquierda. Configuración de 
las elites en el imaginario político chileno dictatorial y el rol de las revistas políticas de oposición, 1973-1989". Bicentenario. Revista de Historia de Chile y América. Vol8. №1:55-86.

2016. "ONG y conocimiento sociopolítico durante la Dictadura: la disputa por el tiempo histórico de la transición. El caso de los Talleres de Análisis de Coyuntura en ECO, 1987-1992" en Revista Izquierdas №27: 1-31.

Munizaga, G. 1984. Revistas y espacio comunicativo, CENECA, Santiago de Chile.

Ossandón, F. 1983. "Lugar de la comunicación popular en la democratización de las comunicaciones en Chile" en La Disputa por la Palabra. Comunicación Popular Alternativa. 2010. ECO editores. Santiago. 17-33.

Patiño, R. 1997. "Intelectuales en transición. Las revistas culturales argentinas (1981-1987) en Cuadernos de RECIENVENIDO. Publicación de curso de Posgraduados en Literatura Española e Hispanoamericana, U. Sao Paulo.
Pecourt, J. 2006. "El campo de las revistas políticas bajo el franquismo"..Papers 81Revista de Sociología: ,205-228.

Proposiciones $\mathrm{N}^{\circ} 1$ al 17, Santiago de Chile, SUR ediciones.

Puryear, J. 1994. Thinking Politics: Intellectuals and Democracy in Chile. 1973-1988, JHU Press.

Rivera,C. 2015. "Diálogos y reflexiones sobre las comunicaciones en la Unidad Popular, 1970-1973". Historia y Comunicación Social, Vol 20, №2: 345-367.,

Rocca, P. 2004. "Por qué, para qué una revista (Sobre su naturaleza y su función en el campo cultural latinoamericano). Hispanoamérica, Año 33, №99: 3-19.

Proposiciones. 1980-1989. Números 1 a 17. Sur ediciones. Santiago.

Saball, P. 2015. Entrevista.

Subercaseaux,B. 2000. Historia del libro. (Alma y cuerpo). LOM Ediciones. Santiago.

http://www.sitiosur.cl/historia.php consultado enero 2016. 